\title{
REPRESENTAÇÕES SOCIAIS SOBRE A PRÁTICA PEDAGÓGICA NOS ANOS FINAIS DO ENSINO FUNDAMENTAL
}

\author{
Received: august/2020
}

Accepted: september $/ 2020$

Available online: september/2020

\begin{abstract}
Silvania Maria da Silva Gil, Mestra em Educação, Unisantos, Brasil. E-mail: silvaniasilva@unisantos.br
\end{abstract}

\begin{abstract}
Resumo: Esta pesquisa, em andamento, intenciona investigar as representações sociais sobre as práticas pedagógicas de professores que atuam nos anos finais do ensino fundamental, que têm estudantes com deficiência matriculados na rede regular de ensino. A partir do referencial teórico da Teoria das Representações Sociais (MOSCOVICI, 2012, 2015) e das técnicas de observação de Altet (2017), busca-se identificar quais práticas são desempenhadas pelos professores em sala de aula e em qual referencial se baseiam. O estudo tem uma abordagem qualitativa de caráter exploratório, realizada através da técnica de evocação, observação de aulas e entrevistas semiestruturadas. Os dados estão sendo organizados e observados através da Análise de Conteúdo (BARDIN, 2007, FRANCO, 2012), ainda em andamento. A partir dos dados analisados até o momento, observa-se que alguns professores já possuem uma visão holística do estudante, mas outros ainda não se sentem preparados, indicando que os estudantes com deficiência têm "falta" ou "ausência" de alguma coisa.
\end{abstract}

Palavras-chave: prática pedagógica, anos finais do ensino fundamental, representações sociais.

\begin{abstract}
This research, in progress, intends to investigate the social representations about the pedagogical practices of teachers who work in the final years of elementary school, who have students with disabilities enrolled in the regular teaching network. Based on the theoretical framework of the Theory of Social Representations (MOSCOVICI, 2012,2015) and the observation techniques of Altet (2017), it is sought to identify which practices are performed by teachers in the classroom and on which framework they are based. The study has a qualitative approach of exploratory character, carried through the technique of evocation, observation of classes and semi-structured interviews. The data are being organized and observed through Content Analysis (BARDIN, 2007, FRANCO, 2012), still in progress. From the data analyzed so far, it is observed that some teachers already have a holistic view of the student, but others still do not feel prepared, indicating that students with disabilities have "lack" or "absence"of something.
\end{abstract}

Keywords: pedagogical practices, in the final years of elementary school, social representations. 
Resumén: Esta investigación en curso pretende investigar las representaciones sociales lãs prácticas pedagógicas de los maestros que trabajan en los últimos años de la escuela primaria, que tienen estudiantes con discapacidades inscritos en el sistema escolar regular. Desde el marco teórico de la Teoria de lãs Representaciones Sociales (MOSCOVICI, 2012, 2015) y las técnicas de observación de Altet (2017), buscamos identificar qué prácticas realizan los maestros en el aula y en qué referencia se basan. El estudio tiene un enfoque cualitativo de carácter exploratorio, realizado a través de la técnica de evocación, observación, observación de clases y entrevistas semi estructuradas. Los dados se están organizando y observando a través del análisis de contenido (BARDIN, 2007, FRANCO, 2012), todavía en curso. A partir de los datos analizados hasta ahora, se observa que algunos maestros ya tienen una visión holística del estudiante, pero otros todavía no se sienten preparados, lo que indica que los estudiantes con discapacidades tienen "falta" o "ausência" de algo.

Palabras clave: prácticas pedagógicas, los últimos años de la escuela primaria, las representaciones sociales.

\section{INTRODUÇÃO}

Partindo da compreensão de que a inclusão é fundamental, pois enfatiza, como apontam Almeida e Abdalla (2017, p. 5), “[...] a necessidade de se alcançar uma educação para todos, centrada no respeito e valorização das diferenças”, busca-se com este trabalho verificar quais são as representações sociais que os professores dos anos finais do ensino fundamental têm sobre suas práticas pedagógicas, nas turmas onde estão matriculados os estudantes, público- alvo da educação especial: estudantes com deficiência, transtornos globais do desenvolvimento, altas habilidades/superdotação.

A democratização do ensino, com a garantia de acesso e permanência na escola, permite que esses estudantes tenham consideradas suas necessidades individuais e possam se desenvolver de acordo com sua capacidade, em ambientes educacionais inclusivos (BRASIL, 2008).

Assim, partindo do conceito de representação social, definido por Moscovici (2012, p. 26), como: "uma modalidade de conhecimento particular que tem por função a elaboração de comportamentos e a comunicação entre indivíduos" (p.26), buscamos compreender o que pensam os professores da rede pública da Baixada Santista a 
respeito da aprendizagem desses estudantes, quais práticas pedagógicas desempenham em sala de aula e em qual referencial se baseiam.

A Política Nacional de Educação Especial na perspectiva da Educação Inclusiva (BRASIL, 2008), documento que rege a educação especial hoje no Brasil, tem como objetivo a presença transversal da educação especial, da educação infantil ao ensino superior. Garante o direito à diferença, na igualdade de direitos à educação. É uma diretriz, de forma que os sistemas de ensino possam formar professores que busquem rever suas práticas pedagógicas e reorganizar a educação especial em concordância com os parâmetros inclusivos.

Nesse sentido, complementam Almeida e Abdalla (2017, p. 6), é necessário “criar ambientes de aprendizagem que sejam versáteis, bem como incentivar a cooperação entre diversos profissionais para o desenvolvimento de práticas de ensino inclusivas e colaborativas".

\section{PROCEDIMENTOS METODOLÓGICOS}

De abordagem metodológica qualitativa, a pesquisa se desenvolve em duas fases: $1^{\text {a }}$ fase, a pesquisa bibliográfica, com objetivo exploratório de investigar estudos e pesquisas no âmbito da educação inclusiva nos anos finais do ensino fundamental e das representações sociais; e $2^{\mathrm{a}}$ fase, a pesquisa de campo, tendo duas etapas: observação, em sala de aula, de professores da rede pública da Baixada Santista, conforme a técnica de observação (ALTET, 2017), já iniciada; e entrevistas semiestruturadas com os respectivos professores.

$\mathrm{Na}$ primeira fase, foram selecionados dez trabalhos, entre os anos de 2008 a 2017, que tiveram como foco identificar as representações sociais que os professores 
têm sobre a presença de estudantes com deficiência em suas salas de aula e a melhor prática pedagógica para promoção de sua aprendizagem. Os estudos, por nós selecionados, revelam os seguintes elementos representacionais: a) a presença na fala das professoras da questão de normal/anormalidade, relacionada ao aluno com deficiência embutida no conceito de corpo perfeito, aquele que o senso comum considera adequado. As docentes destacam também a importância fundamental da professora especialista para auxiliar neste processo inclusivo (ABDALLA, 2016); b) a dificuldade para superar muitos obstáculos à mudança como: os instrumentos, a resistência das famílias, a sobrecarga de trabalho e a própria superação pelo desejo de mudar (PINCOLINE, 2008); c) a imagem do estudante com deficiência, como alguém que tem "falta" ou "ausência" de alguma coisa ou de capacidade, sendo aquele que "foge do padrão", acentuando crenças, convenções e a tradição da cultura escolar (MODESTO, 2008; BARBOSA, 2014); d) posturas ancoradas não só no apoio e incentivo à inclusão. Mas, por outro lado, as representações também se ancoraram em manifestações de dúvidas, negação e atitudes contrárias (MOREIRA, 2012); e, por fim, e) representam o medo do fracasso profissional, pena do aluno por suas dificuldades, raiva pelas dificuldades impostas por ele, o desespero diante do não saber (VASCONCELOS, 2008).

Depreende-se desses estudos que as representações sociais devem ser vistas como uma atmosfera em relação ao indivíduo ou grupo e, sob certos aspectos específicos de nossa sociedade, tornam familiar algo não familiar, ou a própria não familiaridade (MOSCOVICI, 2012). Ainda, segundo Moscovici (2012), esse "algo ausente" - a imagem do aluno normal versus anormal - citado pelas docentes - atinge a todos nós e desencadeia o trabalho de pensamento do grupo, gerando, assim, por meio dessas representações, a tensão necessária para que se possam provocar mudanças. 


\section{DOS RESULTADOS ÀS CONSIDERAÇÕES}

Os dados da pesquisa, até aqui analisados, concluem que as representações sociais dos professores dos anos finais do ensino fundamental sobre suas práticas pedagógicas demonstram divergências quanto ao direito de permanência (ou não) desses estudantes nas classes comuns. Alguns profissionais sugerem que eles permaneçam em ambientes segregados, devido à sua falta de prontidão para a aprendizagem e outros, que eles devam sim, estar nas salas comuns, juntos com os demais. Argumentam que necessitam de um aporte teórico sobre a legislação, sobretudo sobre a Política Nacional de Educação Especial na perspectiva da Educação Inclusiva (BRASIL, 2008) e suas diretrizes. Que esta Política precisaria estar elencada no Projeto Político Pedagógico PPP - da escola, para juntamente com a família dos estudantes público alvo da Educação Especial, estudantes com deficiência, transtornos globais do desenvolvimento, altas habilidades/superdotação, fomentarem uma política de gestão escolar voltada para construção de ambientes inclusivos.

Por fim, indicam a necessidade de promoção de uma formação voltada para a construção de uma prática pedagógica, que consiga atender a esses novos desafios, e que busque caminhos para amenizar a angústia, a insegurança, a sobrecarga de trabalho, sem perder o comprometimento com a responsabilidade social de um ensino que seja acessível a todos.

Nesse sentido, na intenção de tornar familiar o que lhe é desconhecido sobre esse outro-diferente, o professor precisa colocar em jogo suas representações, pois são elas (as representações sociais), que conseguem "incutir um sentido ao comportamento", integrando-o a uma rede de relações, que se traduz por opiniões, 
imagens, retratando, enfim, a "posição e a escala de valores de um indivíduo ou de uma coletividade" (MOSCOVICI, 2015).

\section{REFERÊNCIAS}

ABDALLA, A.P. Representações de professores sobre a inclusão escolar. Dissertação (Mestrado). Universidade Estadual Paulista. São Paulo: UNESP, 2016.

ALMEIDA, P. C.A.; ABDALLA, M. F. B. Formación Inicial de Docentes, Políticas de Inclusión y desarrollo de las Competencias Siglo XXI en Brasil. Informe Estratégia Regional sobre Docentes. OREALC: UNESCO Brasil, 2017.

ALTET, M. A observação das práticas de ensino efetivas em sala de aula: pesquisa e formação. Cadernos de Pesquisa. v.47, n. 166, p.1196-1223, out/dez., 2017.

BARBOSA, K. A. M. Representações sociais de professores dos anos finais do ensino fundamental sobre a aprendizagem de estudantes com deficiência em escolas inclusivas. Dissertação. (Mestrado). Universidade de Brasília. Brasília: UNB, 2014.

BARDIN, L. Análise de Conteúdo. São Paulo: Edições 70, 2007.

BRASIL. Ministério da Educação. Secretaria de Educação Especial. Política Nacional de Educação Especial na Perspectiva da Educação Inclusiva. Brasília: MEC, 2008.

FRANCO, M.L.P.B.Análise de conteúdo. Brasília, 4aedição:Líber Livro, 2012.

MODESTO, V. M. F. Inclusão Escolar: um olhar para a diversidade: as representações sociais de professores do ensino fundamental da rede pública sobre o aluno com necessidades educacionais especiais. Dissertação (Mestrado). Universidade de Brasília, 2008.

MOREIRA, G. E. Representações Sociais de professoras e professores que ensinam matemática pelo fenômeno da deficiência. Tese (Doutorado). Pontifícia Universidade Católica: PUC/ SP, 2012.

MOSCOVICI, S. A psicanálise, sua imagem e seu público. Petrópolis: Vozes, 2012.

MOSCOVICI, S. Representações sociais: investigações em psicologia social. Tradução de Pedrinho A. Guareschi. 11. ed. Petrópolis, RJ: Vozes, 2015. 404 p

PINCOLINE, R. F. O. As representações sociais dos professores sobre a avaliação dos alunos incluídos na rede pública regular de ensino em Santa Maria. Dissertação (Mestrado). Universidade Federal de Santa Maria. Santa Maria: UFSM, 2008.

VASCONCELOS, K. M. Convivendo com a alteridade: representações sobre o aluno com deficiência no contexto da educação inclusiva. Dissertação (Mestrado). Universidade Federal de Pernambuco. Recife: UFP, 2008. 